\title{
Depressive symptoms among children whose parents have serious mental illness: Association with children's threat- related beliefs about mental illness
}

\author{
${ }^{1}$ Lagos State University College of Medicine, Lagos, Nigeria \\ ${ }^{2}$ Berkshire Healthcare Foundation NHS Trust, Berkshire, UK \\ ${ }^{3}$ Centre for Mental Health, Imperial College London, UK
}

B Ola, ${ }^{1}$ MB ChB, FMCPsych, FWACP; R Suren, ${ }^{2}$ MBBS, MRCPsych; C Ani ${ }^{2,3}$ MBBS, MSc, DCH, MRCP, MRCPsych, MD

Corresponding author: C Ani (c.ani@imperial.ac.uk)

\begin{abstract}
Background. Sixty-eight per cent of women and 57\% of men with mental illness are parents. There is increasing evidence of adverse psychosocial impact of parental mental illness on their children. However, among children whose parents have mental illness, the potential contribution of the children's beliefs about mental illness to their own emotional distress is still poorly understood.

Aim. To explore among children whose parents have serious mental illness, the relationship between the children's beliefs about mental illness and their own depressive symptoms.

Methodology. We conducted an interview-administered questionnaire survey of 67 Nigerian children whose parents were psychiatric inpatients. The children's beliefs about mental illness were explored with five questions - two of which embedded threat-related beliefs. Their depressive symptoms were assessed with the Short Mood and Feelings Questionnaire (SMFQ) (Cronbach alpha 0.91). Based on stigma theory, we hypothesised that among this cohort, the children who hold threat-related beliefs about people with mental illness would report statistically significantly more depressive symptoms than those without similar beliefs.

Results. The mean age (standard deviation (SD)) of the children was 13.3 (2.8) years, and 38\% were males. Twenty-four per cent of the children believed mental illness is infectious. In line with our hypothesis, those holding this belief had statistically significantly more depressive symptoms compared with those without similar beliefs $(p=0.001)$. Fifty-seven per cent of the children believed that people with mental illness are dangerous. However, contrary to our hypothesis, this belief was not associated with increased depressive symptoms $(p=0.2)$. Multiple regression showed that statistically significant predictors of increased emotional symptoms were 'belief that mental illness is infectious' and younger age. The model explained $39.8 \%$ of the variance in SMFQ.

Conclusion. In this and similar settings, psycho-education for children whose parents have serious mental illness should explore whether the children believe that mental illness is infectious. Providing reassurance to children holding such beliefs could reduce their risk of psychological distress.
\end{abstract}

S Afr J Psychiatr 2015;21(3):74-78. DOI:10.7196/SAJP.8253

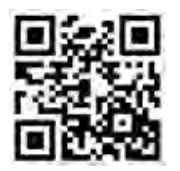

Sixty-eight per cent of women and $57 \%$ of men with mental illness are parents. ${ }^{[1]} \mathrm{A}$ large number of young people are therefore exposed to parental psychiatric conditions. $^{[2]}$ This is likely to be more pertinent in low- and middle-income countries (LAMICs) where parents (including those with mental illness) tend to have more children. ${ }^{[3]}$ Childhood is a critical period of development during which children have physical and psychological vulnerabilities that could be adversely affected by parental mental illness. ${ }^{[4]}$ Although some children show resilience, studies consistently show that parental mental health problems can have a major affect on children with increased risk of behavioural, social, emotional and educational problems. ${ }^{[5]}$ Children of parents with mental illness are at considerable risk to feelings of secure attachment and long-term mental health. Offspring of depressed parents are at greater long-term risk of lower social, psychological and physical health than children of nondepressed parents. ${ }^{[6]}$ These negative outcomes operate through a complex interaction of risk and resiliency factors, which are discussed next.

The potential effect of parental mental illness on dependent children can be direct and indirect. ${ }^{[7]}$ Direct mechanisms include inherited genetic vulnerabilities, exposure to intrauterine toxins such as alcohol and illicit drugs, and perinatal maternal malnutrition. Indirect effects include interference with maternal bonding and child's attachment, suboptimal responsive parenting including limited nurturing and boundary setting, socioeconomic disadvantage, and marital conflict often associated with mental illness. Some of the best evidence of the impact of parental mental illness on children comes from research on depressed parents. ${ }^{[6]}$ This condition has been shown to affect attachment formation and the cognitive, emotional, social and behavioural and physical development of children. The effect on children's physical development is particularly pertinent in LAMICs, where environmental threats to child wellbeing such as malnutrition and poor sanitation are more common. ${ }^{[8]}$ 
In view of the potential effect of parental mental illness on their children's wellbeing, prevention and intervention at an early stage are of great importance. Interventions should focus not only on the treatment of the parent's psychiatric disorder, but also the other factors directly and indirectly affecting the life and wellbeing of their offspring. ${ }^{[7]}$ However, successful intervention depends on better understanding of the modifiable risk factors mediating the negative effect of parental mental illness on children.

One potential source of psychosocial distress for children of parents with mental illness is the children's own beliefs about mental illness. If affected children hold misinformed and/or inaccurate beliefs about mental illness, the associated worry could contribute to the children's own risk of mental illness. This is particularly relevant if the children hold beliefs suggesting risk of personal peril from living with an affected parent. Incidentally, beliefs about mental illness by children of parents with psychiatric disorders have scarcely been explored in the literature. We found no studies that have explored the association of such beliefs with risk of mental distress in affected children. This is the novel hypothesis explored in this study.

\section{Methods}

We conducted an interview-administered questionnaire survey of 67 Nigerian children whose parents were psychiatric inpatients in the mental health unit of the Lagos State University Teaching Hospital. The respondents were children of consecutive adult inpatient admissions over a 2-month period. Patients with one or more children aged between 7 and 18 years were approached when their mental state was stable. No patients or the identified children declined consent. The first child of the patient who visited the hospital was selected. If two or more children visited at the same time, one of the children was selected by a calculator-generated random number. Following written informed consent from parents and the children, the questionnaires were administered to the children in private by trained interviewers. The interviewers were blinded to the study hypothesis to avoid information bias. The study was approved by the Ethics and Research Committee of Lagos State University Teaching Hospital. The conduct of the study met the requirements of the
Helsinki Declaration on the use of human participants in research.

\section{Measurements}

\section{Depressive symptoms}

Depressive symptoms were assessed with the Short Mood and Feelings Questionnaire (SMFQ). ${ }^{[9]}$ This is a brief rating scale for childhood depressive symptoms, which has shown adaption and good psychometrics in many parts of the world, including developing countries such as Pakistan. ${ }^{[10]}$ The instrument showed excellent internal consistency in our sample (Cronbach's alpha 0.91).

\section{Beliefs about mental illness}

The children's beliefs about mental illness were explored with five questions selected from previous studies in Nigeria. ${ }^{[11,12]}$ Three questions ('Mental illness is caused by witches and wizards', 'Mental illness is punishment for sin' and 'Mental illness is not treatable with modern medicine') are commonly held beliefs among a wide spectrum of Nigerians and we encounter these regularly in practice. For purposes of testing our study hypothesis, we included two specific beliefs that represent potential threat to the child from the parent with mental illness ('Mental illness is infectious so can be acquired by being close to an affected person' and 'People with mental illness are dangerous'). Although belief that people with mental illness are dangerous is held commonly worldwide, belief that mental illness is infectious is unusual and has not been reported in the literature. The beliefs were treated individually (rather than summatively) in analysis as we were interested in exploring associations between the specific beliefs and depressive symptoms. We hypothesised that the two beliefs linked directly with potential threat to the child would be associated with depressive symptoms while the other three beliefs would not have similar associations.

\section{Socioeconomic status (SES)}

SES was assessed with a rating based on whether the family owned a number of highvalue possessions such as mobile phones, computer, colour television set, motorcycle, motor car, and a house (Table 1). Additional weighting was given to ownership of a house or car to reflect their relatively higher value. This procedure has been found reliable in previous studies in Nigeria. ${ }^{[13]}$

\section{Analysis}

The data were analysed with SPSS version 18 (IBM, USA). Continuous and categorical data were described with means (and standard deviations (SDs)), and numbers and percentages, respectively. The pattern of missing was random and as recommended by Pallant, ${ }^{[14]}$ all analyses excluded cases only if they were missing data for the particular analysis. The $t$-test was used to conduct bivariate analysis between SMFQ and dichotomous predictor variables (e.g. gender and beliefs about mental illness). Associations between SMFQ and age, as well as socioeconomic rating, were assessed by calculating Pearson correlation coefficients. Chi-square tests were used to explore associations between sets of categorical variables such as gender and questions

Table 1. Sociodemographic and family characteristics

\begin{tabular}{|c|c|}
\hline Variable & $n(\%)$ \\
\hline Age (years), mean (SD) & $13.34(2.87)$ \\
\hline Gender (male) & $24(38.1)$ \\
\hline \multicolumn{2}{|l|}{ Who child lives with: } \\
\hline Both parents & $42(62.7)$ \\
\hline Mother alone & $17(25.4)$ \\
\hline Father alone & $4(6.0)$ \\
\hline Others & $4(6.0)$ \\
\hline \multicolumn{2}{|l|}{ Child attending school: } \\
\hline Yes & $56(83.6)$ \\
\hline No & $11(16.4)$ \\
\hline \multicolumn{2}{|l|}{ Maternal education: $(n=64)$} \\
\hline No or primary education & $20(31.3)$ \\
\hline Secondary education & $25(39.1)$ \\
\hline Postsecondary education & $19(29.7)$ \\
\hline \multicolumn{2}{|l|}{ Paternal education: $(n=61)$} \\
\hline No or primary education & $10(16.4)$ \\
\hline Secondary education & $23(37.7)$ \\
\hline Postsecondary education & $28(45.9)$ \\
\hline \multicolumn{2}{|l|}{$\begin{array}{l}\text { Socioeconomic measures, } \\
\text { family owns: }\end{array}$} \\
\hline Mobile phone & $55(87.3)$ \\
\hline Computer & $21(33.3)$ \\
\hline Colour TV & $45(71.4)$ \\
\hline Motorcycle & $5(8.1)$ \\
\hline Car & $27(41.5)$ \\
\hline House & $21(32.3)$ \\
\hline $\begin{array}{l}\text { Short mood and feelings ques- } \\
\text { tionnaire score, mean (SD) }\end{array}$ & $6.35(5.14)$ \\
\hline
\end{tabular}


on beliefs about mental illness. Predictor variables with statistically significant associations with depressive symptoms were entered into a hierarchical linear regression model to identify independent predictor variables.

\section{Results}

Thirty-eight per cent of the children were males and the mean (SD) age of the whole cohort was 13 (2.9) years, range 7 - 18 years. Most lived with both their parents (63\%). There were no statistically significant differences in mean age between males (13.90(2.64)) and females (12.97(3.00)); $t(61=1.21, p=0.23$. Most of the children were enrolled in schools (84\%) and more than two-thirds of their parents had secondary or higher levels of education. Most of the families owned a mobile phone and a colour television, and almost half owned a car.

Some of the children held inaccurate beliefs about mental illness (Table 2). A quarter believed that mental illness is infectious and a similar proportion believed mental illness is not treatable with modern medications. More than half believed mental illness is caused by witchcraft and that affected persons are dangerous. There were no statistically significant differences in the number of males and females holding these beliefs: (i) mental illness is infectious (males $=3$ $(13.6 \%)$, females $=11(30.6 \%), \chi^{2}=2.1, \mathrm{df}=1$, $p=0.21$ ); (ii) mental illness is dangerous (males $=14(60.9 \%)$, females $=19$ (52.8\%), $\chi^{2}=0.37, \mathrm{df}=1, p=0.60$ ); (iii) mental illness is caused by witches and wizards (males $=9$ (39.1\%), females $=20(55.6 \%), \chi^{2}=1.52, \mathrm{df}=1$, $p=0.29$ ); (iv) mental illness is punishment for $\sin ($ males $=6(26.1 \%)$, females $=12(33.3 \%)$, $\left.\chi^{2}=0.35, \mathrm{df}=1, p=0.77\right) ;(v)$ mental illness is not treatable (males $=5(21.7 \%)$, females $=8$ (22.9\%), $\chi^{2}=0.01, \mathrm{df}=1, p=1.0$ ).

Table 2 shows that children who believed that mental illness is infectious scored statistically significantly higher on the SMFQ (mean (SD) score $=10.75(5.91)$ ) than those who did not hold similar beliefs (5.41 (4.22), $t(56)=3.57, p=0.001)$. The children who believed that mental illness is infectious were statistically significantly younger (mean (SD) age $=12.00(2.48)$ years) than those who did not (13.87 (2.58), $t(60)=-2.47, p=0.016$ ). No other belief about mental illness was statistically significantly associated with SMFQ scores (Table 2) or differed by age.
Depressive symptoms (SMFQ scores) correlated negatively with age $(r=-0.43, n=67$, $p=0.0001)$. Male and female SMFQ scores did not differ significantly (males 6.17 (5.27) v. females 6.36 (4.98); $t(57)=-0.14, p=0.89$.

Hierarchical linear regression model (Table 3) was used to determine if the association between depressive symptoms and belief that mental illness is infectious remains after controlling for age, gender and socioeconomic rating. These three

\section{Table 2. Beliefs about mental illness and association with depressive symptoms}

\begin{tabular}{llll}
\hline & & \multicolumn{2}{c}{ Score on SMFQ } \\
Belief & $n(\%)$ & Mean (SD) & \multicolumn{1}{c}{$\boldsymbol{t}$-test } \\
\hline Mental illness is infectious so can be & & & \\
acquired by being close to an affected person & & & \\
$\quad$ Yes & $15(24.2)$ & $10.75(5.91)$ & $t=3.57, \mathrm{df}=56, p=0.001$ \\
$\quad$ No & $47(75.8)$ & $5.41(4.22)$ & \\
People with mental illness are dangerous & & & \\
$\quad$ Yes & $36(57.1)$ & $7.11(4.98)$ & $t=1.29, \mathrm{df}=57, p=0.20$ \\
$\quad$ No & $27(42.9)$ & $5.37(5.16)$ & \\
Mental illness is caused by witches and & & & \\
wizards & & & \\
$\quad$ Yes & $32(50.8)$ & $6.34(5.37)$ & $t=-0.09, \mathrm{df}=57, p=0.93$ \\
$\quad$ No & $31(49.2)$ & $6.46(4.88)$ & \\
Mental illness is punishment for sin & & & \\
$\quad$ Yes & $20(31.7)$ & $6.10(5.34)$ & $t=-0.31, \mathrm{df}=57, p=0.75$ \\
$\quad$ No & $43(68.3)$ & $6.55(5.02)$ & \\
Mental illness is not treatable with modern \\
medicine
\end{tabular}

Table 3. Regression coefficients for independent predictors of Short Mood and Feelings Questionnaire (SMFQ)

\begin{tabular}{|c|c|c|c|}
\hline Variable & $B$ & $S E B$ & $\beta$ \\
\hline \multicolumn{4}{|l|}{ Step 1} \\
\hline Age & -0.86 & 0.24 & $-0.46^{*}$ \\
\hline Gender $^{\dagger}$ & -0.34 & 1.28 & -0.3 \\
\hline Socioeconomic rating & -0.11 & 0.16 & -0.08 \\
\hline \multicolumn{4}{|l|}{ Step 2} \\
\hline Age & -0.58 & 0.23 & $-0.30^{\ddagger}$ \\
\hline Gender $^{\dagger}$ & -0.77 & 1.16 & -0.08 \\
\hline Socioeconomic rating & -0.30 & 0.16 & -0.24 \\
\hline Belief that mental illness is infectious ${ }^{\S}$ & -5.29 & 1.50 & $-0.45^{*}$ \\
\hline $\begin{array}{l}\text { Notes. } R^{2}=0.24 \text { for Step } 1(p<0.01) ; \Delta R^{2}=0.16 \text { for Ste } \\
{ }^{*} p<0.01 . \\
{ }^{+C} \text { Coded: 'male' }=1 \text {, 'female' }=2 . \\
{ }^{\ddagger} p<0.05 \text {. } \\
{ }^{\text {'Coded: }} \text { 'yes' }=1 \text {, 'no' }=2 .\end{array}$ & & & \\
\hline
\end{tabular}


close to the line, Durbin-Watson score of 1.72 showed the data met the assumption of independent errors, while Variance Inflation Factor (VIF) scores in the range of $1.05-1.25$, and Tolerance scores in the range of $0.80-0.96$ show that multicollinearity was not a concern. ${ }^{[15]}$ Although our sample size was small, the inclusion of four variables in the regression model is consistent with the 'ten cases per variable' recommended by Pallant. ${ }^{[14]}$

Entering age, gender and socioeconomic rating in the first step produced a statistically significant model $(\mathrm{F}(3,49)=5.19, p=0.003)$, which explained $24 \%$ of the variance in depressive symptoms $\left(R^{2}=0.24\right)$. Entry of belief that mental illness is infectious alone in the second block further increased the variance explained by $16 \%$ $\left(\Delta R^{2}=0.16\right)$. The final model was statistically significant $(\mathrm{F}(4,48)=7.93$, $p=0.0001)$ and showed that belief that mental illness is infectious was a statistically significant and independent predictor of increased depressive symptoms. The other statistically significant predictor was younger age and the final model explained $39.8 \%$ of the variance in depressive symptoms.

\section{Discussion}

This study explored the association between holding threat-related beliefs about mental illness and depressive symptoms among children whose parents have psychiatric disorders. Consistent with our hypothesis, we showed that belief that mental illness is infectious was a statistically significant predictor of depressive symptoms in this cohort. We believe this is a novel finding with important implications for the psychoeducation of children whose parents have mental illness.

Erroneous belief about causation and lack of adequate knowledge have been found to sustain deep-seated negative attitudes towards mental illness. ${ }^{[16]}$ As serious infectious diseases such as tuberculosis and HIV are common in many LAMICs, especially in Africa, it is reasonable to hypothesise that children become socialised early in life to the potency and peril associated with infectious diseases. This can induce fear and lower threshold for perceived sense of threat from illness they consider infectious. This could feed into helplessness, sense of isolation and loss of control, impacting on the young person's mood.

This finding has potential implications for clinical practice in this setting. Psychoeducation for the whole family, particularly the children, about the mental illness is a key component in the treatment strategy for affected persons. ${ }^{[17]}$ Our findings suggest that this should involve exploration of the attitude and understanding of their children about mental illness, as the children could be holding unfounded beliefs and fears that could be contributing to their emotional distress. To this end, where a child or other family members believe that mental illness is infectious, they can be categorically and unequivocally reassured that this is not the case. Although this study focused on children, it is worth including other family members and the parent with mental illness in the discussion. The reason is that the family unit is the primary source of socialisation for children, ${ }^{[18]}$ so it is likely that their beliefs have been formed from beliefs held by other family members. We are unsure how this applies to other LAMICs or high-income countries as this specific association has not been explored in those settings. However, where similar associations are found, it would be appropriate to provide similar reassurance about mental illness not being infectious.

We were surprised that the belief that people with mental illness are dangerous was not associated with depressive symptoms. This is contrary to our hypothesis. We wonder if this lack of association relates to the high prevalence of this belief in our sample $(57 \%$ compared with $24 \%$ for belief that mental illness is infectious). In fact, the former belief was the most commonly held of all five beliefs presented to the children. Incidentally, belief that people with mental illness are dangerous is also commonly held worldwide in both lowand high-income countries. ${ }^{[16]}$ We therefore suspect that the high prevalence of this belief makes it 'normative' to a degree that perhaps diffuses the sense of specific threat that may otherwise cause distress to children who hold it. This is unlike the belief that mental illness is infectious, which is unusual.

In this study, younger age was also a statistically significant predictor of higher depressive symptoms. This could be because the younger children are less familiar with mental illness - so more likely to hold threat-related beliefs. In fact, this was the case in our study. In line with Nigerian traditional family hierarchy, the younger children are less likely to be included in discussions about their parent's mental illness either at home with relatives or with professionals in clinics and hospitals. Therefore, they may have misconceptions and fears which they are unable to discuss and clarify. The younger children may also have less access to alternative sources of information such as the internet and mental health publications. If they do, they may not be able to independently understand the information as a result of their relatively lower level of cognitive development. Their willingness to ask adults for clarity may be limited by the expectation of deference by children to adults and authority figures in Nigeria. Breach of this expectation could be interpreted as disrespect which can attract punishment including physical discipline. ${ }^{[19]}$

The findings of our study should be interpreted in the light of some limitations, including the small sample size that was sourced from one tertiary referral hospital. This limits the generalisability of the findings. Also the cross-sectional design means no causal association could be implied. The questionnaire-based assessment of psychopathology without clinical interview means that only depressive symptoms rather than depressive disorder could be measured. The finding that only $38 \%$ of our sample were males is consistent with the tradition in our setting for females to carry out more caring roles, such as visiting ill parents in hospital and providing them with material and emotional support.

\section{Conclusion}

In conclusion, despite the above limitations, our study suggests that for children and families where a parent has a serious mental illness, psychoeducation, which is a key aspect of therapeutic intervention, should include exploration of threat-related attitudes and beliefs about mental illness. Where such are found, accurate information should be provided and reassurance offered where appropriate. This could reduce the risk of depressive symptoms in affected children.

Acknowledgement. We thank the children and their parents for kindly agreeing to participate in this study. 


\section{References}

1. Royal College of Psychiatrists. Parental mental illness: The impact on children and adolescents: Information for parents, carers and anyone who works with young people. http:// www.rcpsych.ac.uk/healthadvice/parentsandyouthinfo/parentscarers/parentalmentalillness. aspx (accessed 18 January 2015).

2. Bassani DG, Cintia V, Padoin CV, Philipp D, Veldhuizen S. Estimating the number of children exposed to parental psychiatric disorders through a national health survey. Child Adolesc Psychiatry Ment Health 2009;3:6. [http://dx.doi.org/10.1186/1753-20003-6]

3. Patel V, Flisher AJ, Nikapota A, Malhotra S. Promoting child and adolescent mental health in low and middle income countries. J Child Psychol Psychiatry 2008;49(3):313-334. [http:// dx.doi.org/10.1111/j.1469-7610.2007.01824.x]

4. Gladstone BM, Boydell KM. MCkeever P. Recasting research into children's experiences of parental mental illness: Beyond risk and resilience. Soc Sci Med 2006;62(10):2540-2550. [http://dx.doi.org/10.1016/j.socscimed.2005.10.038]

5. Singleton L. Parental mental illness: The effects on children and their needs. Br J Nur 2007;16(14):847-850. [http://dx.doi.org/10.12968/bjon.2007.16.14.24321]

6. Weissman MM, Wickramaratne P, Nomura Y, Warner V, Pilowsky D, Verdeli H. Offspring of depressed parents: 20 years later. Am J Psychiatry 2006;163(6):1001-1008. . [http://dx.doi. org/10.1176/appi.ajp.163.6.1001]

7. Manning C, Gregoire A. Effects of parental mental illness on children. Psychiatry 2006;5(1):10-12. [http://dx.doi.org/10.1383/psyt.2006.5.1.10]

8. Rahman A, Malik A, Sikander S, Roberts C, Creed F. Cognitive behaviour therapy-based intervention by community health workers for mothers with depression and their infants in rura Pakistan: A cluster-randomised controlled trial. Lancet 2008;372(9642):902-909. [http://dx.doi. org/10.1016/s0140-6736(08)61400-2
9. Angold A, Costello EJ, Messer SC, Pickles A, Winder F, Silver D. The development of a short questionnaire for use in epidemiological studies of depression in children and adolescents. Int J Methods Psychiatr Res 1995;5:237-249.

10. Imran N, Ani C, Mahmood Z, Hassan K, Bhatti M. Anxiety and depression predicted by medically unexplained symptoms in Pakistani children: A case-control study. J Psychosom Res 2014;76(2):105-112. [http://dx.doi.org/10.1016/j.jpsychores.2013.11.016]

11. Adewuya AO, Makanjuola RO. Social distance towards people with mental illnes in southwestern Nigeria. Aus N Z J Psychiatry 2008;42:389-395. [http://dx.doi. org/10.1080/00048670801961115]

12. Ani C, Ola B, Coker R. School children's stigmatising attitude towards peers with epilepsy in Nigeria Vulnerable Child Youth Stud 2011;6(4):330-338. [http://dx.doi.org/10.1080/17450128.2011.630491]

13. Ani C, Grantham-McGregor S. Family and personal characteristics of aggressive Nigerian boys: Differences from and similarities with western findings. J Adolesc Health 2008;23(5):311-317. [http://dx.doi.org/10.1016/s1054-139x(98)00031-7]

14. Pallant J. SPSS Survival Manual, 3rd ed. Maidenhead, UK: Open University Press, 2007.

15. Field A. Discovering Statistics Using SPSS, 2nd ed. London: Sage Publications, 2005.

16. Corrigan P, Watson A. Understanding the impact of stigma on people with mental illness. World Psychiatry 2002;1(1):16-20.

17. McFarlane W, Dixon L, Lukens E, Lucksted A. Family psychoeducation and schizophrenia A review of the literature. J Marital Fam Ther 2003;29(2):223-245. [http://dx.doi. org/10.1111/j.1752-0606.2003.tb01202.x]

18. Belsky J. Family influences on psychological development. Psychiatry 2008;7(7):282-285 [http://dx.doi.org/10.1016/j.mppsy.2008.05.006]

19. Chianu E. Two deaths, one blind eye, one imprisonment: Child abuse in the guise of corpora punishment in Nigerian schools. Child Abuse Negl 2000; 24(7):1005-1009. [http://dx.doi. org/10.1016/s0145-2134(00)00154-x] 